Article

\title{
An Optimal Collocation Strategy for the Key Components of Compact Photovoltaic Power Generation Systems
}

\author{
Pi-Yun Chen, Kuei-Hsiang Chao * and Zih-Yi Wu \\ Department of Electrical Engineering, National Chin-Yi University of Technology, Taichung 41170, Taiwan; \\ chenby@ncut.edu.tw (P.-Y.C.); aegissons@yahoo.com.tw (Z.-Y.W.) \\ * Correspondence: chaokh@ncut.edu.tw; Tel.: +886-4-2392-4505 (ext. 7272); Fax: +886-4-2392-2156
}

Received: 17 July 2018; Accepted: 3 September 2018; Published: 21 September 2018

\begin{abstract}
The objective of this study was to develop an optimal evaluation system for collocating photovoltaic (PV) modules and power conditioners by using the extension engineering method. The matter-element model and correlation functions of the extension theory were adopted as the basis of the proposed extension evaluation system, which was then used to develop a multilevel evaluation model for PV modules and PV power conditioners. The extension evaluation system was used to evaluate and test numerous PV modules and power conditioner products that are commonly employed and commercially available in Taiwan. First, a PV module matter-element model was established based on price, power temperature, size, and weight, and a PV power conditioner matter-element model was established based on input voltage range, maximum power point tracking (MPPT) voltage range, number of MPPT units, minimum operating voltage, and maximum input current. Second, the weighting values of the various characteristics in the extension method were determined according to numerous consideration factors of the PV modules and power conditioners. Finally, the values of the degree of correlation between numerous user preferences and the various PV modules and power conditioner brands were calculated using correlation functions to determine the key components of PV power generation systems (PV-PGSs) that corresponded to user preferences. The test results confirmed that the proposed extension evaluation system can determine the optimal collocation for the key components of the PV-PGSs under different user preference settings.
\end{abstract}

Keywords: photovoltaic module; extension evaluation system; extension theory; photovoltaic power generation system; optimal collocation strategy

\section{Introduction}

The design and configuration processes of photovoltaic power generation systems (PV-PGSs) are extremely complicated, causing interested engineers to withdraw from the field of renewable energy applications. In particular, collocating series and parallel photovoltaic (PV) arrays by using appropriate PV power conditioners to comply simultaneously with safety regulations and maximize the power generation efficiency is a major problem for designers. When designing PV-PGSs, the key technologies that designers must consider include: (1) the fitness between power conditioner capacitance and system setup capacitance, (2) collocating PV arrays with either multistring or single-input power conditioners, (3) brand and type of PV modules employed in PV-PGSs, and (4) designing the number of series and parallel units on PV modules [1]. The selection of the best PV module for the PV system design by using an analytical hierarchy process (AHP) was presented in Reference [2]. After considering electrical, mechanical, financial, environmental, and customer satisfaction performance of each PV module, one can select the most appropriate PV modules in different location or countries. However, this 
proposed evaluation system does not permit adjusting weighting values according to user preferences to determine customized and optimized collocation. In order to obtain a high evaluation quality of a PV module in reality, the decision strategy of PV module selection under an interval value intuitionist fuzzy environment was proposed in Reference [3]. Although the PV modules can be evaluated from the perspectives of engineering management and supply chain management to solve the comprehensive problem of an evaluation index system, this study does not determine the optimal PV module/PV power conditioner collocation in developing compact PV-PGSs. Reference [4] proposed a selection and configuration of PV modules and power conditioners for a PV system to minimize costs. However, this evaluation method requires complex computations and can only be achieved at the lowest price and cannot be achieved at the highest efficiency in power generation.

The present study thus proposes an optimal strategy for selecting key components within a PV-PGS by developing a set of optimal solutions to resolve the flaws of designing PV-PGSs, thereby enabling general engineers to design efficient PV-PGSs according to different setup environments and customer demands.

The procedures involved in implementing the proposed strategy are highlighted as follows: First, the specifications of all PV modules within a 305-W capacity range were derived from the PV module registry website [5] hosted by the Bureau of Energy, Ministry of Economic Affairs. The information of each module was classified, and a list of all the parameters commonly valued in the PV industry was created. The extension theory [6] was then adopted to establish a matter-element model for the various PV module specification values, where a weighting value was awarded to each matter element based on its level of significance. Next, the correlation functions of each matter element were calculated to determine the elements' degrees of correlation. The size of the correlation was then examined to formulate the optimal selection strategy for the PV modules. Finally, this study changed the weighting values of the various matter elements according to specific user demands, such as setup cost and setup site, to determine a PV module that met user demands.

Second, specifications of the most commonly used power conditioner products with a capacitance of approximately $5 \mathrm{kWp}$ were collected from the PV inverter registry website [7] hosted by the Bureau of Energy, Ministry of Economic Affairs. The extension theory was then adopted to establish a matter-element model for the various power conditioner specification values, where a weighting value was awarded to each matter element according to its level of significance. Next, the correlation functions of each matter element were calculated to determine the degrees of correlation of the elements. The size of correlation was then examined to formulate the optimal selection strategy for power conditioners. Finally, this study changed the weighting values of the various matter elements according to numerous user-specified factors to determine a power conditioner that satisfied user demands.

Third, the optimal PV module and power conditioner were collocated to create the optimal PV-PGS. Initially, several optimal PV modules were connected in series and in parallel to create PV arrays that have an appropriate capacitance. The key parameters for selecting the power conditioner were determined and a weighting value was awarded to these parameters according to the various characteristics described in the extension theory. After determining the degree of correlation for each of the parameters by calculating correlation functions, this study formulated the optimal strategy for selecting the key components within PV-PGSs. In addition, this study changed the weighting values of the various factors according to different user demands and factor levels to produce PV-PGSs that met user demands. The proposed decision-making method is advantageous in that it includes simple parameters that can be easily compiled in the decision-making process. Furthermore, this method can also be used to produce formal tables and equations; this can facilitate the tasks of designers in calculating and promoting this method, thereby increasing user acceptance and considerably contributing to the development of the PV industry. 


\section{Extension Theory}

Prof. Tsai Wen, a Chinese scholar, introduced the extension theory in $1983[6,8,9]$. This theory combines the matter-element theory with extension mathematics. The matter-element theory primarily promotes computation and inference processes based on potential event changes, matter element conversion, and matter element transformation. By contrast, extension mathematics promotes computation and inference processes based on mathematical systems created from extension sets, correlation functions, and extension logic. In the extension theory, a matter-element model, in which the qualitative and quantitative relationships of events undergo matter element conversion, is established. Correlation functions are then calculated to determine the degree of correlation between quality, quantity, and events.

Classical mathematics is typically employed to classify events into specific membership sets. In this method, binary logic is used in the classification process, where 1 represents a match and 0 represents a mismatch. However, classification becomes ambiguous in the fuzzy zones, rendering the classical mathematics method obsolete. The extension theory expands binary logic into a multifunctional logic by using correlation functions to express event characteristics clearly. In other words, the extension theory uses real numbers that range from $-\infty$ to $\infty$ to determine the relationships that specific elements have on the membership grade of event characteristics. These real numbers are also called the correlation degree that elements have on the membership set of the event characteristics. If the values of the degree of correlation are not normalized, a greater correlation degree indicates that the event matches the specific characteristics better, whereas a smaller correlation degree, even negative, represents more of a mismatch. A correlation degree between $-\infty$ and $\infty$ represents the degree of correlation between the element and event property.

\subsection{Basic Theory of Matter Elements}

Names and characteristics are typically assigned to events to distinguish between different event types and phenomena. Even similar events may demonstrate differences in style, pattern, or construct. The extension theory uses matter-element models to present such differences. The matter-element math table can be expressed as follows:

$$
R=(N, C, V)
$$

where $R$ represents the basic element of an event (alternatively called a "matter element"), $N$ represents the event name, $C$ represents the event characteristic, and $V$ represents the characteristic value. Furthermore, $N, C$, and $V$ constitute the three factors of matter elements. If $R$ presents $n$ number of characteristics, the characteristics and characteristic values can be expressed in vector form. This characteristic vector can be expressed as $C=\left[\begin{array}{llll}c_{1} & c_{2} & \cdots & c_{n}\end{array}\right]^{T}$, and the corresponding value vector can be expressed as $V=\left[\begin{array}{llll}v_{1} & v_{2} & \cdots & v_{n}\end{array}\right]^{T}$. Thus, the resulting vector can be expressed as follows:

$$
R=(N, C, V)=\left[\begin{array}{ccc}
N, & c_{1}, & v_{1} \\
& c_{2}, & v_{2} \\
& \vdots & \vdots \\
& c_{n}, & v_{n}
\end{array}\right]
$$

\subsection{Extension Set Theory}

When the characteristic value is a range, this range is denoted as the classical domain, which is confined within the range of a neighborhood domain. Assume a zone of $F_{0}=\langle a, b\rangle, F=\langle g, h\rangle$, and 
$F_{0} \in F$. If $F_{0}$ is a random point in $F$, then $F_{0}=\langle a, b\rangle$. The corresponding matter elements can thus be expressed as follows:

$$
R_{0}=\left[\begin{array}{ccc}
F_{0}, & c_{1}, & v_{1} \\
& c_{2}, & v_{2} \\
\vdots & \vdots \\
& c_{n}, & v_{n}
\end{array}\right]=\left[\begin{array}{ccc}
F_{0}, & c_{1}, & <a_{1}, b_{1}> \\
& c_{2}, & <a_{2}, b_{2}> \\
\vdots & \vdots \\
& c_{n}, & <a_{n}, b_{n}>
\end{array}\right]
$$

where $c_{n}$ represents the characteristic of $F_{0}, v_{n}$ denotes the characteristic value of $c_{n}$ (also called the classical domain), $a_{n}$ represents the lower bound of the classical domain, and $b_{n}$ denotes the upper bound of the classical domain. The matter elements $\left(R_{F}\right)$ corresponding to the neighborhood domain (F) can be expressed as follows:

$$
R_{F}=\left(F, C_{m}, V_{m}\right)=\left[\begin{array}{ccc}
F, & c_{1}, & <g_{1}, h_{1}> \\
& c_{2}, & <g_{2}, h_{2}> \\
\vdots & \vdots \\
c_{n}, & <g_{n}, h_{n}>
\end{array}\right]
$$

where $C_{m}$ represents the characteristic of $F, V_{m}$ denotes the characteristic value of $C_{m}, g_{n}$ represents the ceiling of the neighborhood domain, and $h_{n}$ denotes the floor of the neighborhood domain.

As shown in Table 1, classical sets use a two-value concept (i.e., 0 and 1) to determine whether events possess specific characteristics. The fuzzy theory uses a membership function to assign the degree of membership of fuzzy sets within a range of $0-1$. In contrast to fuzzy sets, which demonstrate a range of $0-1$, extension sets expand the set range to $-\infty$ to $\infty$, which can also be used to explain the characteristic degree.

Table 1. Comparison between the three types of aggregate set functions.

\begin{tabular}{cccc}
\hline Item & Cunction & Fuzzy Set & Extension Set \\
\hline Objective & Data variability & Linguistic variability & Incompatibility problem \\
Model & Mathematical model & Fuzzy rule base & $\begin{array}{c}\text { Matter-element model } \\
\text { Correlation function }\end{array}$ \\
Function Description & Transfer function & Set function & Extension \\
Event Characteristic & Accurate & Fuzzy & $K_{A}(x) \in[-\infty, \infty]$ \\
Set Function Range & $C_{A}(x) \in[0,1]$ & $\mu_{A}(x) \in[0,1]$ & \\
\hline
\end{tabular}

\subsection{Extension Correlation Functions}

An extension correlation function is a type of extension set that describes two or more domains based on the correlation degree and variability of the elements within the domains. To establish the correlation functions in real domains, the distance concept of real variable functions must be converted to "distance" concepts. In the extension theory, the classical domain $F_{0}=[a, b]$ and neighborhood domain $F=[g, h]$ are the two zones of the real domain $[-\infty, \infty]$, where $F_{0} \subset F$. Assuming $x$ is a point in the real domain, then the correlation functions can be defined as follows:

$$
\begin{gathered}
D\left(x, F_{0}, F\right)=\left\{\begin{array}{cc}
\rho(x, F)-\rho\left(x, F_{0}\right) & , x \notin F_{0} \\
-1 & , x \in F_{0}
\end{array}\right. \\
k(x)=\frac{\rho\left(x, F_{0}\right)}{D\left(x, F_{0}, F\right)}
\end{gathered}
$$

where

$$
\rho\left(x, F_{0}\right)=\left|x-\frac{a+b}{2}\right|-\frac{b-a}{2}
$$




$$
\rho(x, F)=\left|x-\frac{g+h}{2}\right|-\frac{h-g}{2}
$$

The greater the value of the correlation function $k(x)$, the higher the correlation degree between element $x$ and the interval in question is. The extension correlation function of $x$ is shown in Figure 1 . Furthermore, $k(x)$ represents the degree of correlation between $x$ and $F_{0}$. When $k(x) \geq 0, k(x)$ can be considered the degree of membership of $x$ in $F_{0}$.

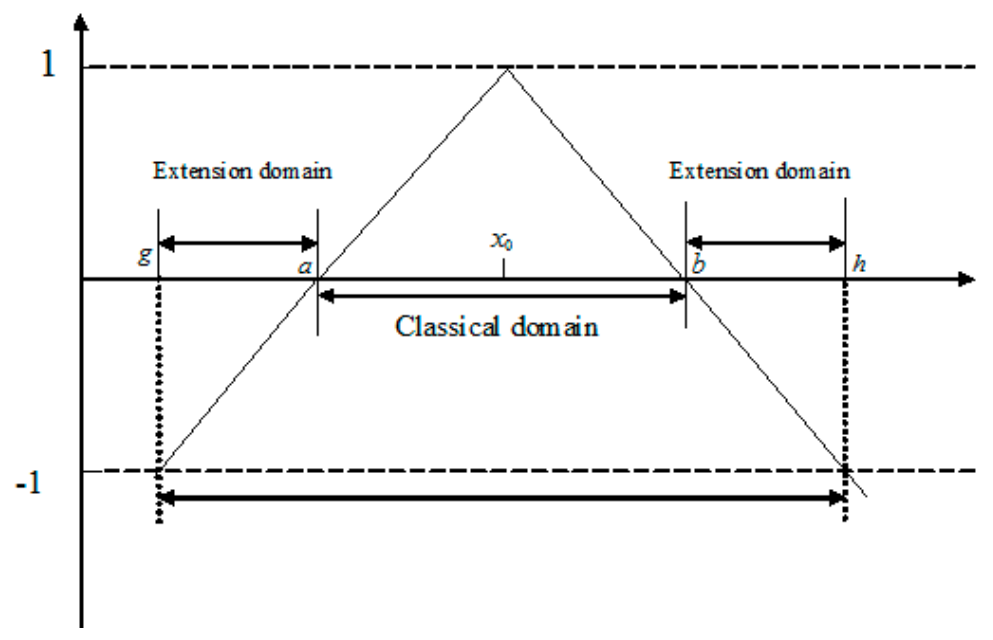

Figure 1. Extension correlation functions.

\subsection{Extension Decision Procedures}

Regarding the extension evaluation system proposed in the present study, a Matlab computer calculation program (R2016a, MathWorks, Natick, MA, USA) was used to develop a decision optimization system. The procedures involved in calculating the evaluation system are described as follows:

Step 1: Based on the characteristics and characteristic value ranges of the various classified events, establish a classical domain matter-element model $\left(F_{0}\right)$ and corresponding neighborhood domain matter-element model $(F)$ for each event.

Step 2: Establish the test matter elements and a matter-element model by using the characteristic values of these test matter elements, as expressed in Equation (9).

$$
R_{x}=\left[\begin{array}{ccc}
F_{x}, & c_{1}, & v_{x 1} \\
& c_{2}, & v_{x 2} \\
& \vdots & \vdots \\
& c_{n}, & v_{x n}
\end{array}\right]
$$

Step 3: Use Equations (5) and (8) to calculate the correlation functions $\left(K_{i j}(x)\right)$ between the various characteristics within the test matter elements $\left(R_{x}\right)$ and the matter-element characteristics of the various events $(j)$.

Step 4: Based on the significance of the characteristics, award a weighting value $\left(W_{j=1,2, \cdots, n}\right.$, where $n$ represents the number of characteristics) to each of the characteristics.

Step 5: Calculate the degree of correlation between the test matter elements $(x)$ and various events $(i)$ by using Equation (10).

$$
K_{i}(x)=\sum_{j=1}^{n} W_{j} K_{i j}(x), \quad i=1,2, \cdots, m
$$


where $m$ represents the number of classified events.

Step 6: Determine suitable events based on the calculation results. An increased correlation value $\left(K_{i}(x)\right)$ represents a greater correlation between test matter element $(x)$ and the matter element of the event. An increased correlation represents a higher degree of suitability. Suitability can be expressed as follows:

$$
K_{\max }(x)=\max \left[K_{i}(x) ; \quad i=1,2, \cdots, m\right]
$$

As for how to use the proposed extension method, the detail is also presented as a flowchart in Figure 2.

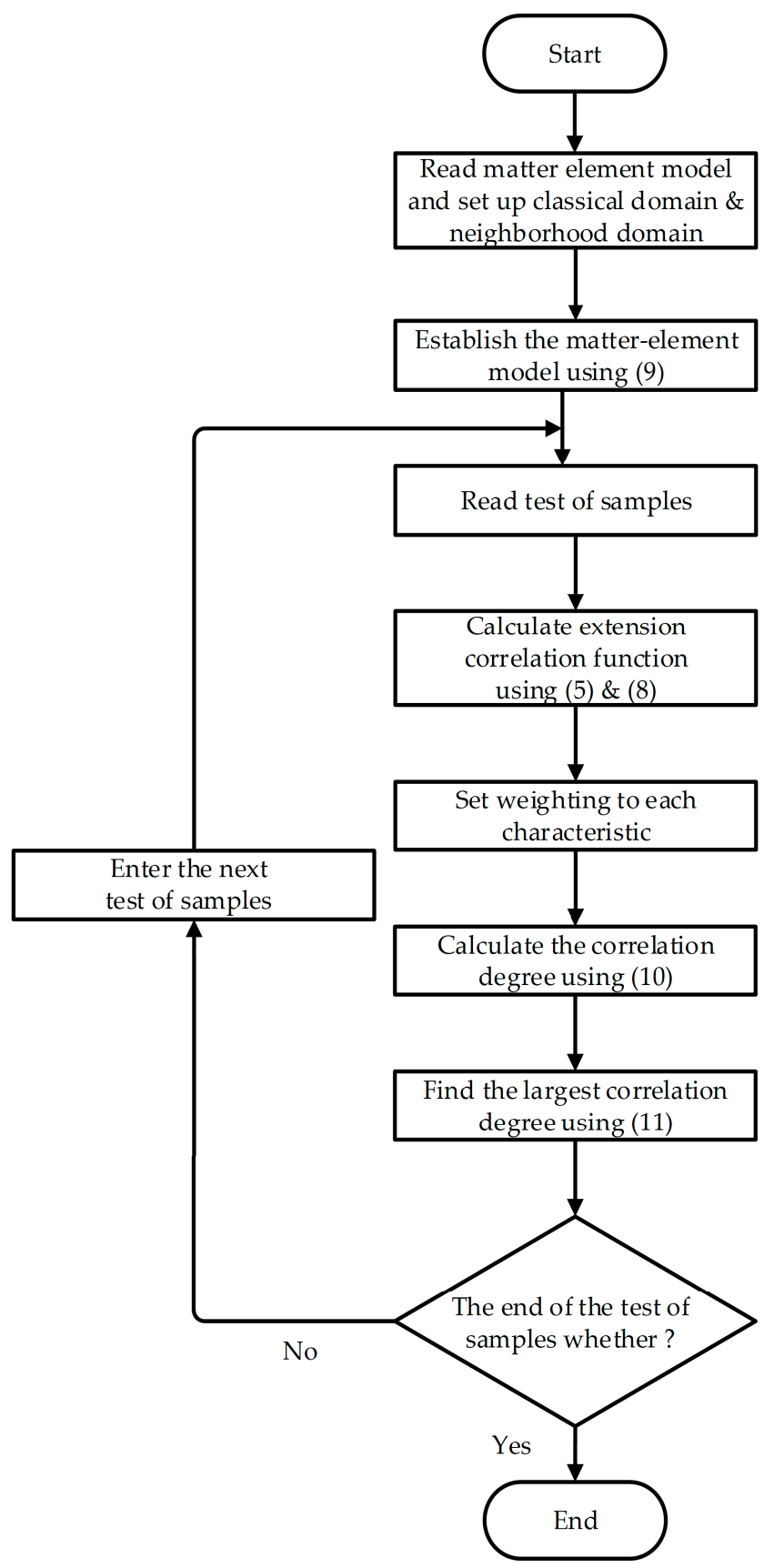

Figure 2. The flowchart of the proposed extension decision procedures. 


\section{Optimal PV Module Selection for the PV-PG}

PV modules are affected by irradiation intensity and temperature. Therefore, the effects of the open-circuit voltage temperature and maximum power point temperature must be considered when designing the selected process. In this context, key parameters of PV modules must first be identified. The parameters serve as element characteristics, each receiving a weighting value. The extension theory is then employed to select the most suitable PV module. Simultaneously, the weighting values of the various element characteristics can be changed according to the degree of importance users place on the key parameters, thereby determining the most suitable PV module under different circumstances. The evaluation method employed in the present study is detailed in the following section.

\subsection{Collecting PV Module Data and Selecting Characteristic Values}

The present study used 305-W monocrystalline and polycrystalline PV modules and 130-160-W copper indium gallium selenide (CIGS) PV modules, which are commercially available in Taiwan [7], as the sample population. However, environment temperatures may cause the output voltage of the PV modules to fluctuate, where a reduced output voltage decreases the overall output power of the PV array. This is a considerable loss for wholesale power capacity. Thus, the coefficient of the power temperature of the modules is a key factor when selecting PV modules. In densely populated countries like Taiwan, the average households typically occupy a limited plot of land; therefore, such households prefer PV-PGSs that employ compact PV modules. However, these PV modules must also demonstrate high conversion efficiencies to achieve the expected generation capacity for consumption or sales. Therefore, the extent of PV modules is a key factor in the selection process. Because the conversion efficiency of the module is related to its size (area), considering its size as a factor here is already considering its conversion efficiency. The PV-PGS promotion policy in Taiwan encourages users to install PV-PGSs on the rooftops of their homes. However, previous construction regulations were not as stringent as present regulations; furthermore, the load-bearing capacity of buildings must be considered before installing PV-PGSs on rooftops. If buildings cannot bear the weight of an entire PV-PGS and require structural reinforcement, which is extremely costly, users may become reluctant and withdraw from installing these systems. Therefore, module weight is also a key factor in selecting PV modules. In addition to the electrical parameters and specifications, the price of PV modules is also a key factor of consideration for both the industry and individual users. A reduced product shipping price increases profits for the vendor and decreases the cost price for the buyer, who may then use the surplus funds for other purposes. Therefore, module price is a key factor to consider.

In summary of the aforementioned consideration factors, this study collected the PV module data from various manufacturers and compiled these data as shown in Table 2 [10-19]. 
Table 2. Key parameters and specifications of the various 305-W monocrystalline and polycrystalline PV modules, and the CIGS PV modules [7].

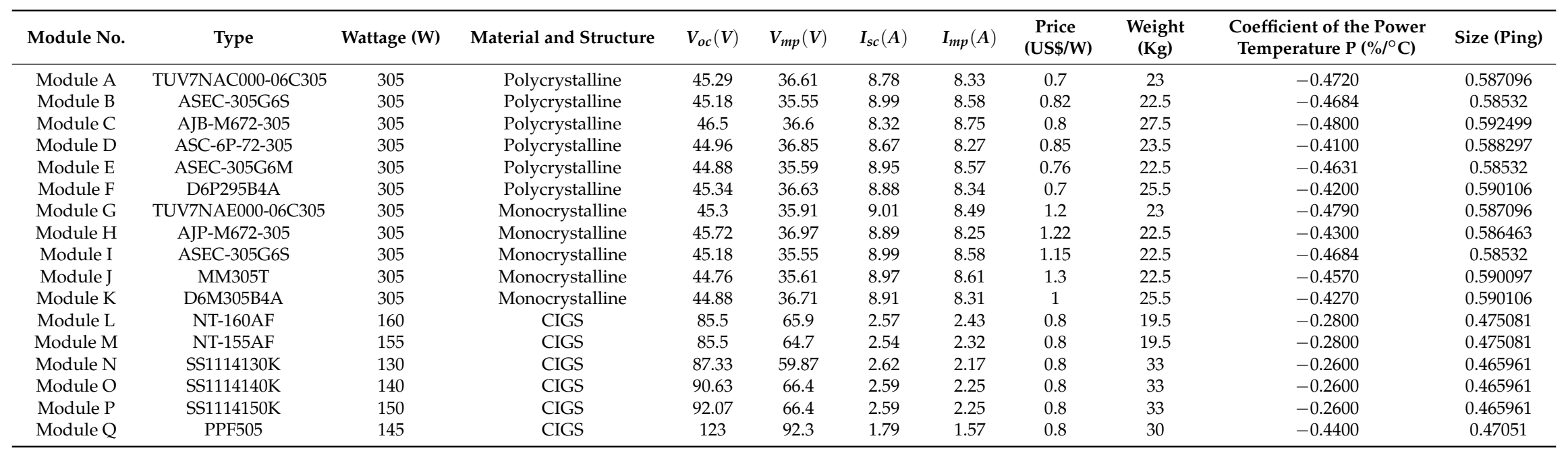




\subsection{Establishing the Extension Matter Elements for the PV Module}

The PV module consideration factors highlighted in the previous section serve as the characteristics in developing the matter-element model. However, the generation efficiency of the PV modules differs depending on the module material and power size. This study classified and compared the PV modules. PV modules with similar materials or similar power sizes were classified into groups and expressed as matter elements. For example, the classical domain matter elements of the 305-W polycrystalline PV module produced by Manufacturer A [7] can be expressed as follows:

$$
R_{A}=\left[\begin{array}{lll}
\text { Poly }- \text { Si } & \text { Price } & <0.75> \\
& \text { Power temperature } & <-0.4720> \\
& \text { Size } & <0.587096> \\
& \text { Weight } & <23>
\end{array}\right]
$$

\subsubsection{Grading the PV Modules}

This study classified the 305-W polycrystalline PV modules into six classes based on price, power temperature, size, and weight. Table 3 shows the grades for each class. Only a few 305-W monocrystalline PV module and CIGS module brands are commercially available in Taiwan and were therefore classified into Classes 5 and 3, respectively.

Table 3. PV module class table.

\begin{tabular}{cc}
\hline Class & Grade \\
\hline 1 & Excellent \\
2 & Very good \\
3 & Good \\
4 & Acceptable \\
5 & Poor \\
6 & Very poor \\
\hline
\end{tabular}

\subsubsection{Defining the PV Module Matter-Element Model}

The grades of the classical domain and neighborhood domain matter-element models of the various PV modules listed in Table 2 are discussed in the Appendix.

According to the classical domain of the Appendix A.1, its neighborhood domain can be obtained from Section 3.2 as follows:

$$
R_{305-P}=\left[\begin{array}{lll}
\text { Poly }- \text { Si } & \text { Price } & <0.70,0.85> \\
& \text { Power temperature } & <-0.48,-0.41> \\
& \text { Size } & <0.58532,0.592499> \\
& \text { Weight } & <22.5,27.5>
\end{array}\right]
$$

According to the classical domain of the Appendix A.2, its neighborhood domain can be obtained from Section 3.2 as follows:

$$
R_{305-S}=\left[\begin{array}{lll}
\text { Mono }- \text { Si } & \text { Price } & <1,1.3> \\
& \text { Power temperature } & <-0.479,-0.427> \\
& \text { Size } & <0.58532,0.590106> \\
& \text { Weight } & <22.5,23>
\end{array}\right]
$$


According to the classical domain of the Appendix A.3, its neighborhood domain can be obtained from Section 3.2 as follows:

$$
R_{\text {CIGS }}=\left[\begin{array}{lll}
\text { CIGS } & \text { Price } & <0.8,0.8> \\
& \text { Power temperature } & <-0.44,-0.26> \\
& \text { Size } & <0.465961,0.475081> \\
& \text { Weight } & <19.5,33>
\end{array}\right]
$$

\subsection{Results of the PV Module Selection}

This study conducted a selection test for module optimization by using the extension method based on factors of price, power temperature, size, and weight, as well as the importance users placed on these factors. The decision-making method proposed in this paper does not require training data, nor does it require a training process. After the system development is completed, as long as the users input the maximum and minimum range of electrical specification data of PV modules and power conditioners, they can find out the optimal combination of PV modules and power conditioners. Therefore, the engineers can find out the optimal combination of system equipments without even knowing how the evaluation method works.

\subsubsection{Selection Results for Price as the Primary Factor of Consideration}

When the order of importance users placed on the four factors were, in sequence, price, power temperature, size, and weight, the characteristic weighting values for these factors were set at 0.5 , $0.25,0.15$, and 0.1 , respectively. The selection test results for similar PV modules listed in Table 2 are separately shown in Figures 3-5; these selection results were derived using the extension method. The performance levels of the modules were evaluated using the extension method and the results indicate that the modules with increased correlation degrees were the more favorable candidates for selection. As shown in Figure 3, when price was the primary factor of consideration for the 305-W polycrystalline PV modules listed in Table 2, Module F was the most favorable candidate for selection because it demonstrated the highest degree of correlation (0.534852). By contrast, Module $C$ was the least favorable candidate because its degree of correlation was the lowest $(-0.438781)$ among the modules. As shown in Figure 5, CIGS Modules N, O, or P were the most favorable candidates for selection when price was the primary factor of consideration.

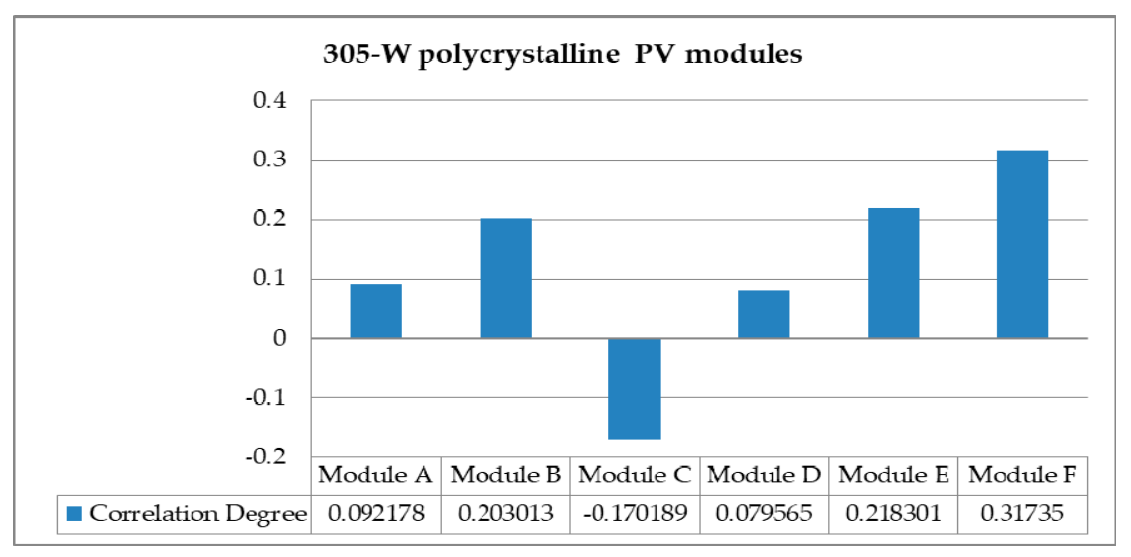

Figure 3. Selection results for the $305-\mathrm{W}$ polycrystalline PV modules when price was the primary factor of consideration. 


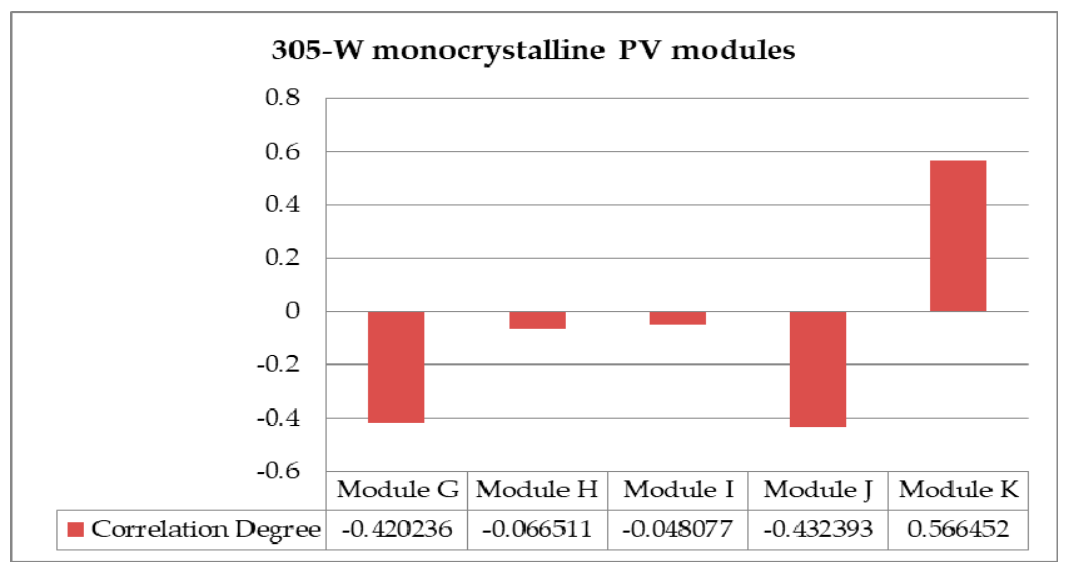

Figure 4. Selection results for the 305-W monocrystalline PV modules when price was the primary factor of consideration.

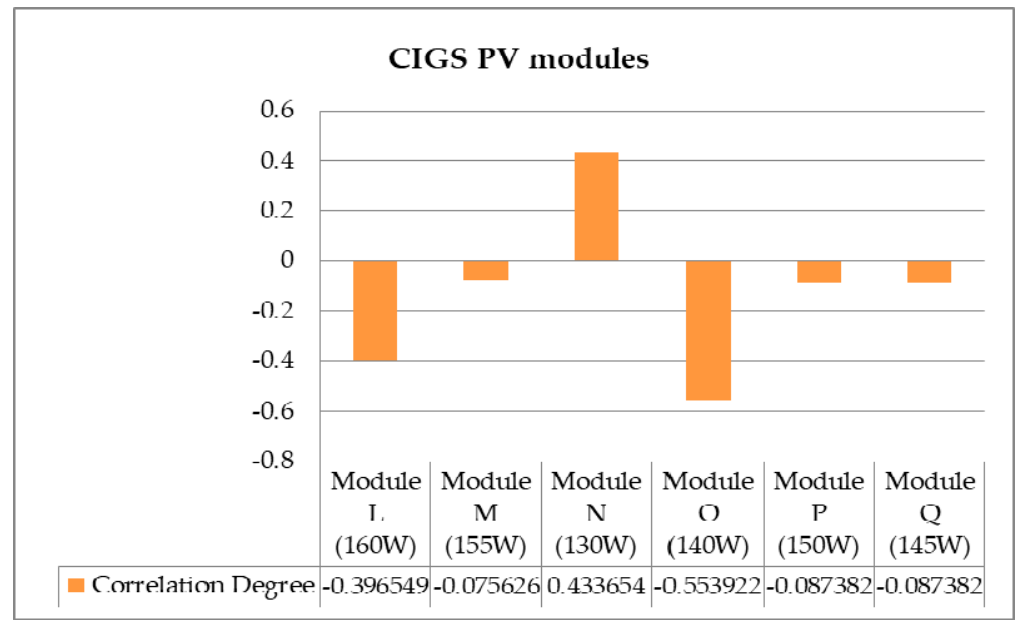

Figure 5. Selection results for the CIGS PV modules when price was the primary factor of consideration.

\subsubsection{Selection Results for Power Temperature as the Primary Factor of Consideration}

When the order of importance users placed on the four factors were, in sequence, power temperature, price, size, and weight, the characteristic weighting values for these factors were set at $0.5,0.25,0.15$, and 0.1 , respectively. The selection test results for similar PV modules listed in Table 2 are separately shown in Figures 6-8; these selection results were derived using the extension method. The performance levels of the modules were evaluated using the extension method, and results indicated that the modules with increased correlation degrees were the more favorable candidates for selection. As shown in Figure 6, when power temperature was the primary factor of consideration for the 305-W polycrystalline PV modules listed in Table 2, Module D was the most favorable candidate for selection because it demonstrated the highest degree of correlation (0.426369) among the modules. By contrast, Module $\mathrm{C}$ was the least favorable candidate because it had the lowest degree of correlation $(-0.683973)$ among the modules. These selection results were not consistent with those obtained when price was the primary factor of consideration. As shown in Figure 8, the CIGS Modules N, O, or P were the most favorable candidates for selection when power temperature was the primary factor of consideration, and these results were consistent with those obtained when price was the primary factor of consideration. This was primarily because power temperature imposed a limited effect on the power output of the CIGS modules. 


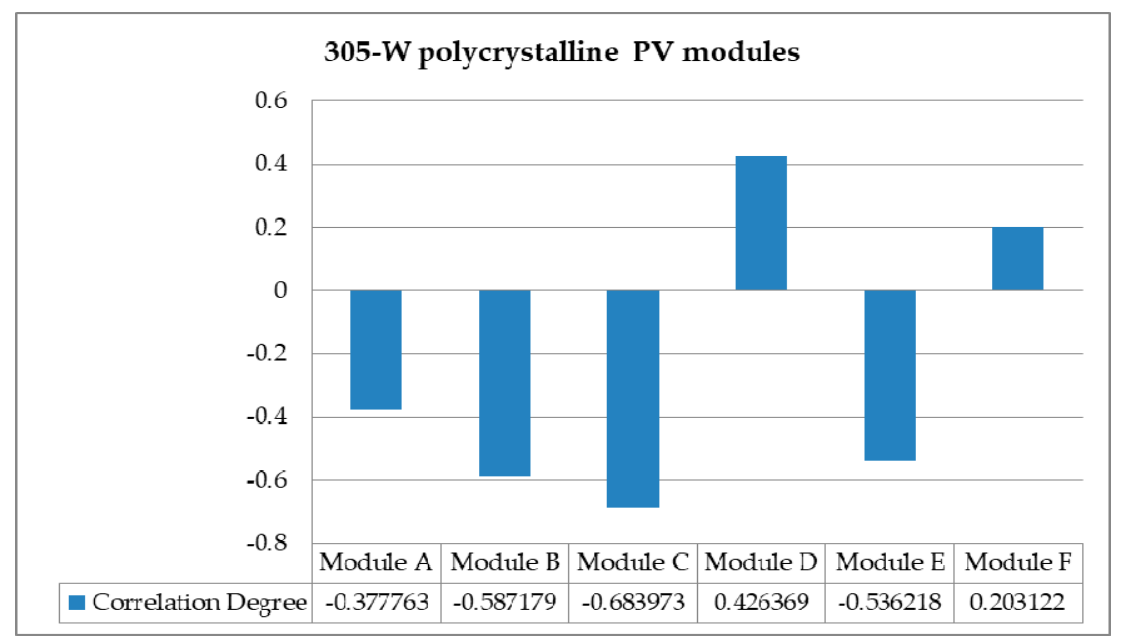

Figure 6. Selection results for the 305-W polycrystalline PV modules when power temperature was the primary factor of consideration.

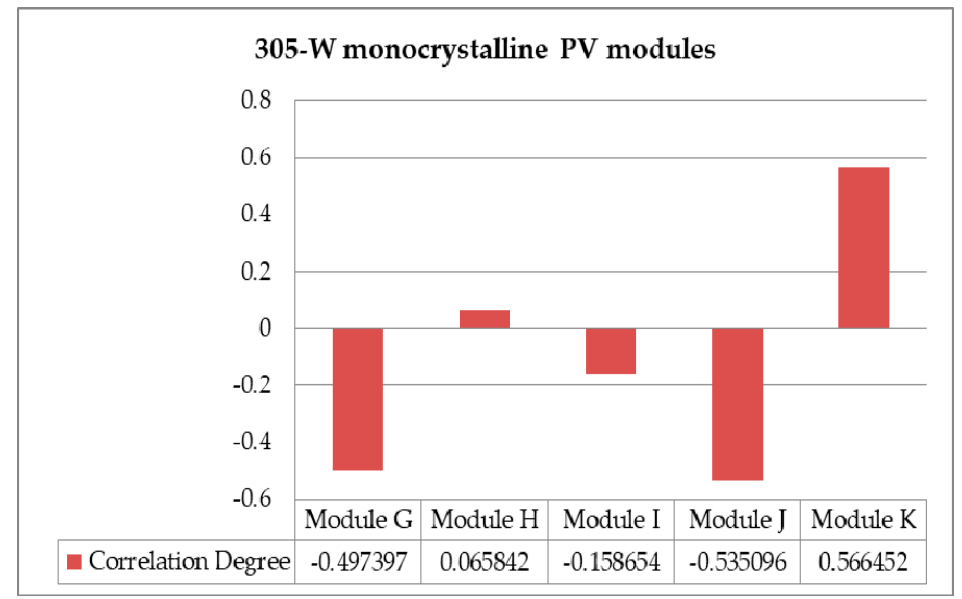

Figure 7. Selection results for the 305-W monocrystalline PV modules when power temperature was the primary factor of consideration.

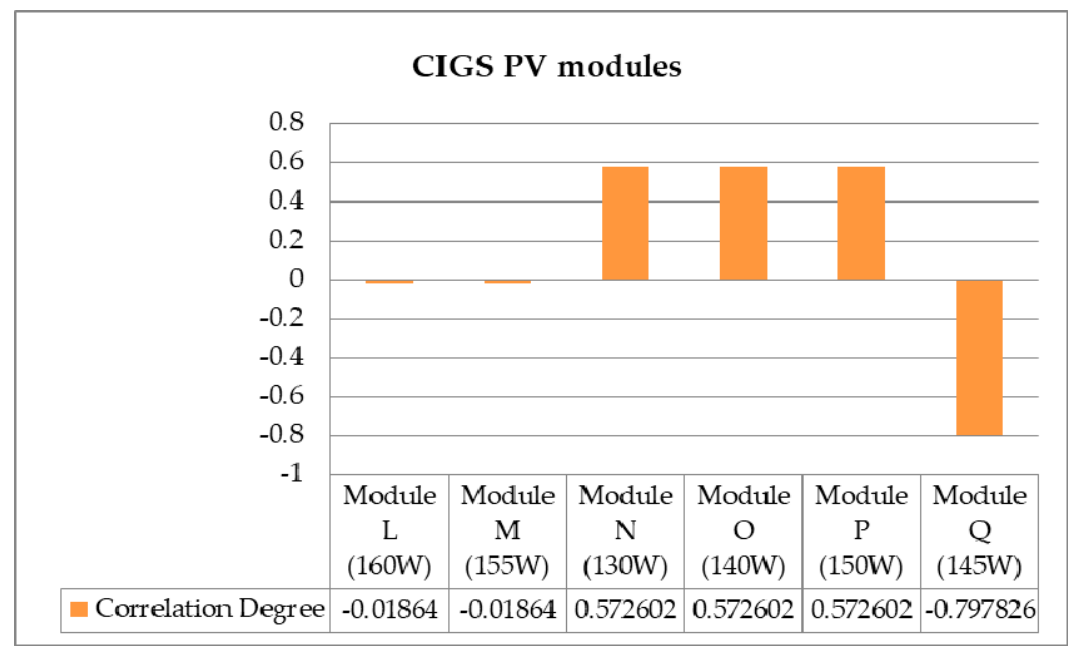

Figure 8. Selection results for the CIGS PV modules when power temperature was the primary factor of consideration. 


\subsubsection{Selection Results for Size as the Primary Factor of Consideration}

When the order of importance users placed on the four factors were, in sequence, size, price, power temperature, and weight, the characteristic weighting values for these factors were set at 0.5 , $0.25,0.15$, and 0.1 , respectively. The selection test results for similar PV modules listed in Table 2 are separately shown in Figures 9-11; these selection results were derived using the extension method. The performance levels of the modules were evaluated using the extension method, and the results indicate that the modules with increased correlation degrees were the more favorable candidates for selection. As shown in Figure 9, when size was the primary factor of consideration for the 305-W polycrystalline PV modules listed in Table 2, Module F was the most favorable candidate for selection because it demonstrated the highest degree of correlation (0.317350) among the modules. By contrast, Module $\mathrm{C}$ was the least favorable candidate because it had the lowest degree of correlation $(-0.170189)$ among the modules. As shown in Figure 11, the CIGS Modules N, O, or P were the most favorable candidates for selection when size was the primary factor of consideration.

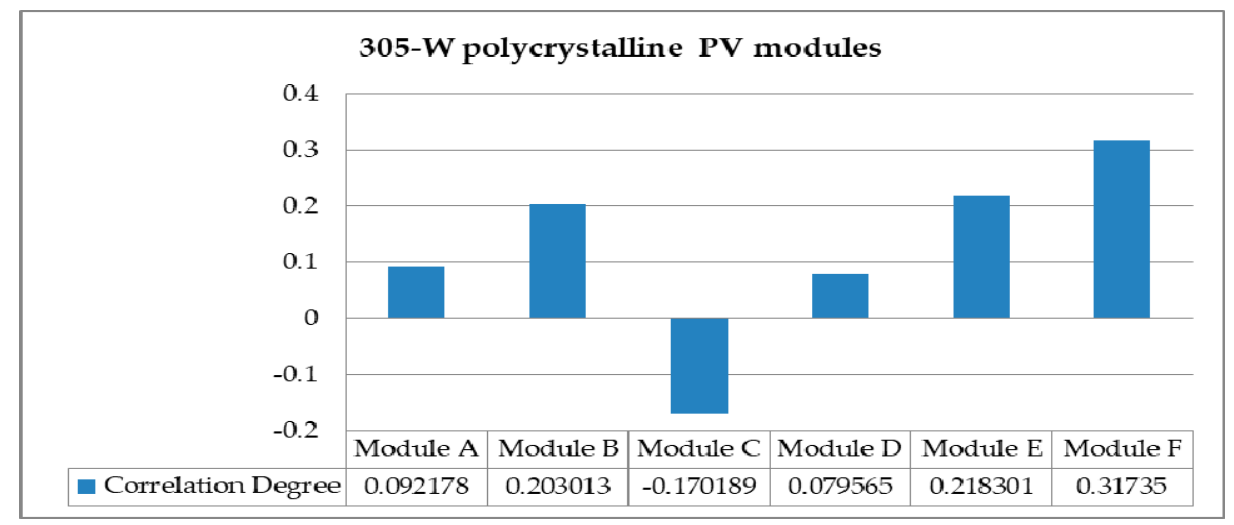

Figure 9. Selection results for the 305-W polycrystalline PV modules when size was the primary factor of consideration.

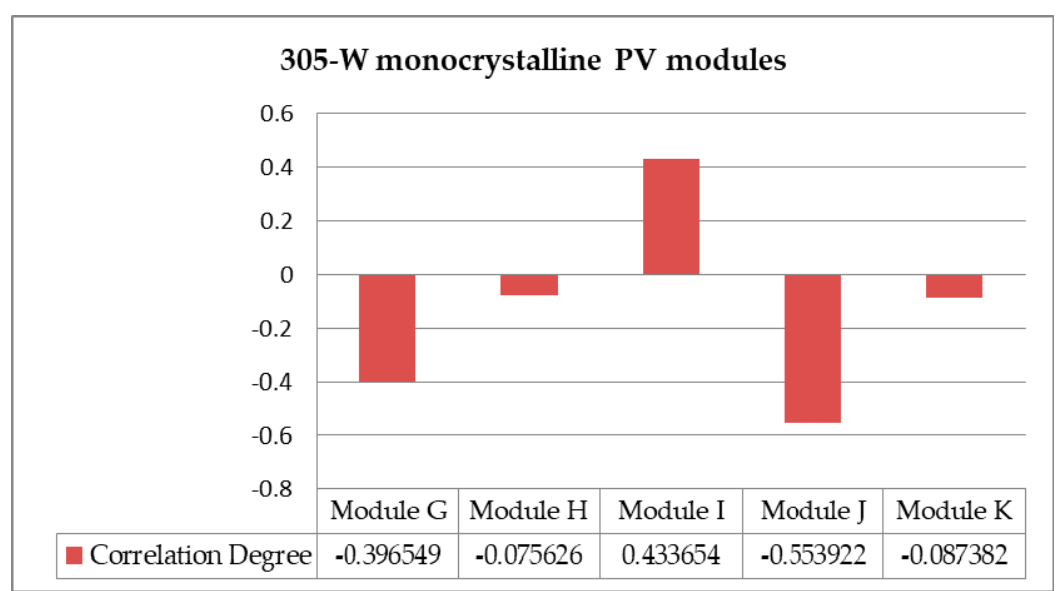

Figure 10. Selection results for the 305-W monocrystalline PV modules when size was the primary factor of consideration. 


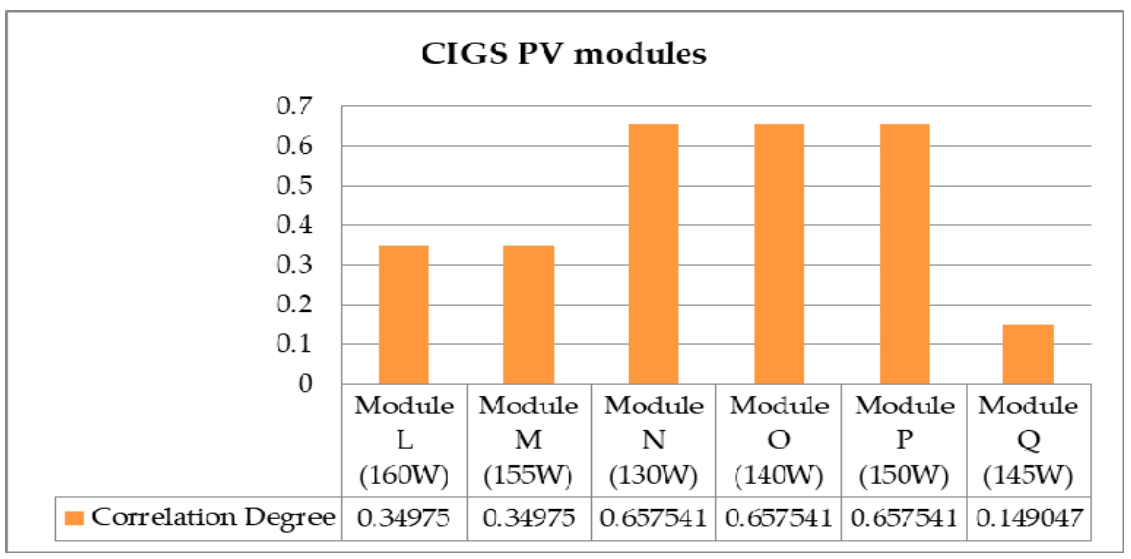

Figure 11. Selection results for the CIGS PV modules when size was the primary factor of consideration.

\subsubsection{Selection Results for Weight as the Primary Factor of Consideration}

When the order of importance users placed on the four factors were, in sequence, weight, price, size, and power temperature, the characteristic weighting values for these factors were set at 0.5 , $0.25,0.15$, and 0.1 , respectively. The selection test results for similar PV modules listed in Table 2 are separately shown in Figures 12-14. The performance levels of the modules were evaluated using the extension method, and the results indicated that the modules with increased correlation degrees were the more favorable candidates for selection. As shown in Figure 12, when weight was the primary factor of consideration for the 305-W polycrystalline PV modules listed in Table 2, Module F was the most favorable candidate for selection because it exhibited the highest degree of correlation (0.800558) among the modules. By contrast, Module B was the least favorable candidate because it demonstrated the lowest degree of correlation $(-0.017436)$ among the modules. As shown in Figure 14, the CIGS Modules $\mathrm{L}$ or $\mathrm{M}$ were the most favorable candidates for selection when weight was the primary factor of consideration.

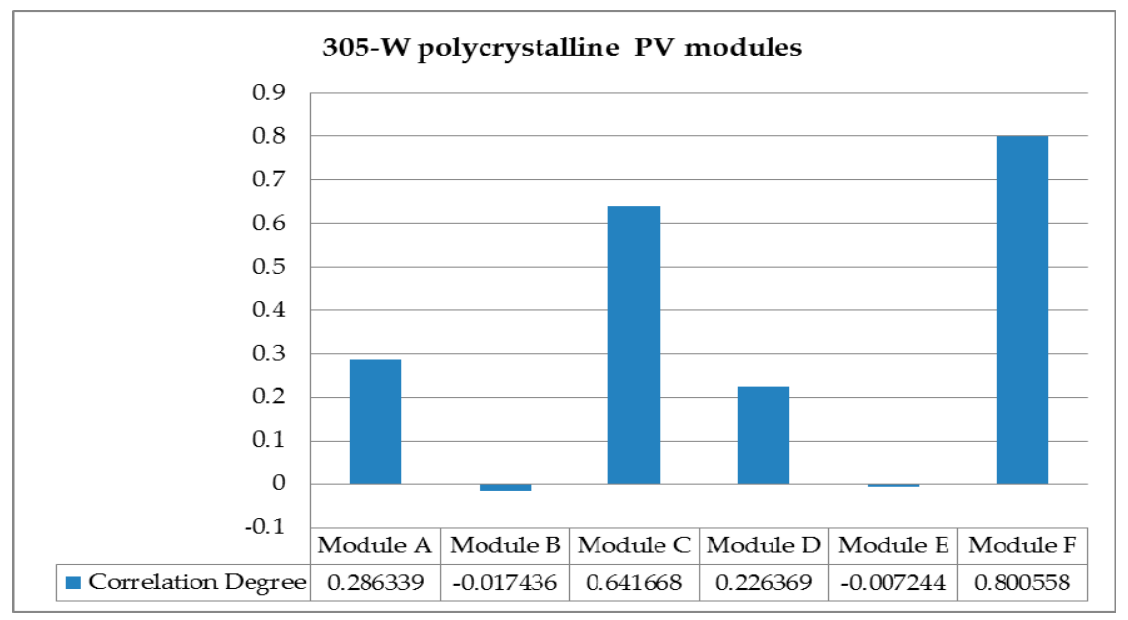

Figure 12. Selection results for the $305-\mathrm{W}$ polycrystalline PV modules when weight was the primary factor of consideration. 


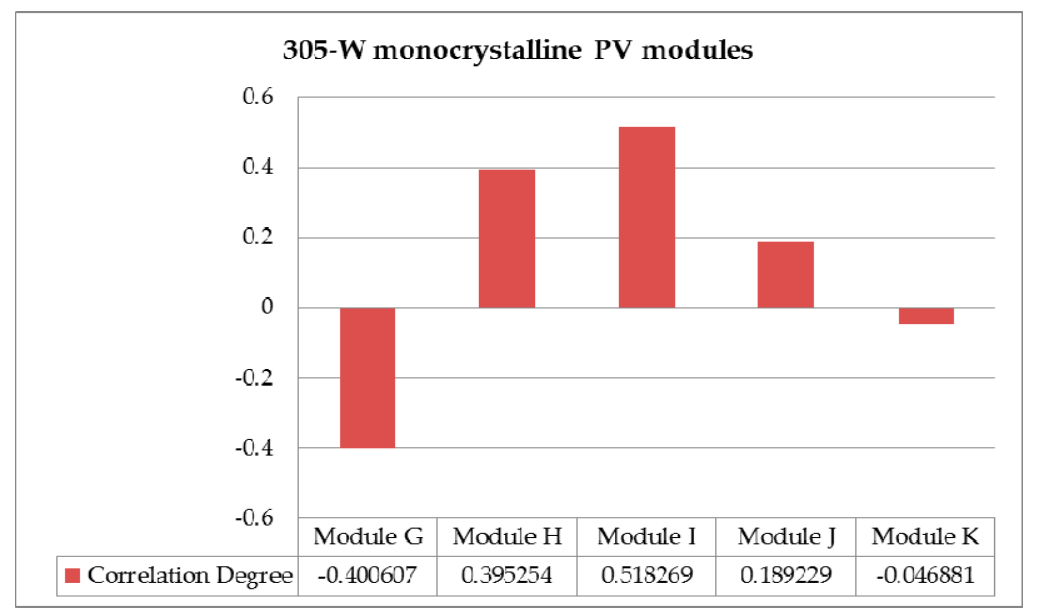

Figure 13. Selection results for the $305-\mathrm{W}$ monocrystalline PV modules when weight was the primary factor of consideration.

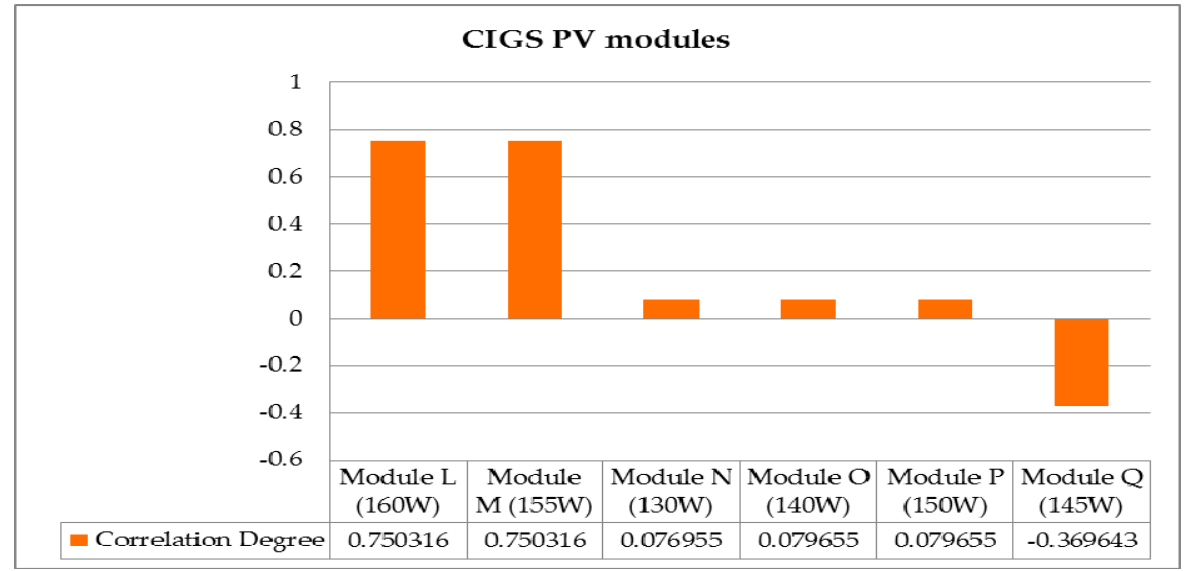

Figure 14. Selection results for the CIGS PV modules when weight was the primary factor of consideration.

\section{Optimal Power Conditioner Selection for PV-PGSs}

\subsection{Collecting Power Conditioner Data and Selecting Characteristic Values}

Power conditioners may differ depending on brand and product specifications. Therefore, the maximum power point tracking (MPPT) voltage range, number of MPPT units, input voltage range, starting voltage, and size of input current are factors of consideration during the selection of power conditioners. When these key parameters are converted into matter elements, the weighting values of these elements can be analyzed using the extension theory to determine the optimal power conditioner. In addition, the weighting values of the matter elements can be modified according to numerous user-specified factors to determine power conditioners that comply with different user demands.

Specifications of the most commonly used power conditioner products can be collected from the PV inverter registry website [7] hosted by the Bureau of Energy, Ministry of Economic Affairs. The power conditions registered on the website are those inspected and approved by the Bureau of Energy, Ministry of Economic Affairs. However, because an excessive amount of power conditioners are registered on the website, the current study used the $5-\mathrm{kWp}$ power conditioners that are commercially available in Taiwan [5] as the sample population. Table 4 lists the eight most commonly used power conditioner models that are commercially available in Taiwan and their specifications [20-27]. The parameters of these power conditioners were selected as the characteristics for the power conditioner selection. 
Table 4. Electrical parameters of the various 5-kWp power conditioners.

\begin{tabular}{cccccc}
\hline Brand & $\begin{array}{c}\text { Input Voltage } \\
\text { Range }(V)\end{array}$ & $\begin{array}{c}\text { MPPT Voltage } \\
\text { Range (V) }\end{array}$ & $\begin{array}{c}\text { MPPT } \\
\text { Number }\end{array}$ & $\begin{array}{c}\text { Starting } \\
\text { Voltage (V) }\end{array}$ & $\begin{array}{c}\text { Maximum Input } \\
\text { Current (A) }\end{array}$ \\
\hline Power conditioner \#1 & $\approx 200-850$ & $\approx 310-800$ & 1 & 235 & 17 \\
Power conditioner \#2 & $\approx 150-650$ & $\approx 150-500$ & 2 & 150 & 15 \\
Power conditioner \#3 & $\approx 120-500$ & $\approx 120-450$ & 2 & 120 & 18.3 \\
Power conditioner \#4 & $\approx 100-580$ & $\approx 290-500$ & 2 & 100 & 9 \\
Power conditioner \#5 & $\approx 100-580$ & $\approx 290-500$ & 2 & 100 & 9 \\
Power conditioner \#6 & $\approx 125-550$ & $\approx 175-440$ & 2 & 150 & 15 \\
Power conditioner \#7 & $\approx 120-500$ & $\approx 150-450$ & 2 & 120 & 18.3 \\
Power conditioner \#8 & $\approx 200-550$ & $\approx 200-550$ & 2 & 235 & 25 \\
\hline
\end{tabular}

\subsection{Defining the Power Conditioner Matter-Element Model}

Based on the various characteristics of the sample population of the power conditioners, the input voltage range, MPPT voltage range, number of MPPT units, starting voltage, and maximum input current of the power conditioners can be described using the five-dimension matter-element model expressed in Equation (13), where $<a_{i j}, b_{i j}>$ represents the range of the various characteristic values (i.e., classical domain of the matter-element model).

$$
R_{x}=\left[\begin{array}{cll}
\text { Brand } & \text { Input voltage range } & <a_{11}, b_{11}> \\
\text { MPPT voltage range } & <a_{12}, b_{12}> \\
\text { MPPT number } & <a_{13}, b_{13}> \\
\text { Starting voltage } & <a_{14}, b_{14}> \\
\text { Maxmum input current } & <a_{15}, b_{15}>
\end{array}\right]
$$

where the neighborhood domain can be expressed as follows:

$$
R=\left[\begin{array}{clc}
\text { Power conditioner } & & \\
& \text { Input voltage range } & <100,850> \\
& \text { MPPT voltage range } & <120,800> \\
& \text { MPPT number } & <001,002> \\
& \text { Starting voltage } & <100,235> \\
& \text { Maxmuminput current } & <005,025>
\end{array}\right]
$$

When the definitions of the aforementioned model are used, the matter-element models of the various power conditioner models listed in Table 4 can be created according to their characteristic value ranges.

\subsection{Selecting the Weighting Values}

This study employed an analytical hierarchy process (AHP) [28] to determine the weighting values used in the proposed power conditioner extension evaluation system. The power conditioner extension evaluation system was processed using the AHP and the resulting weighting values for the input voltage range, MPPT (maximum power point tracking) input range, numbers of MPPT units, starting voltage, and maximum input current were $0.3,0.383,0.163,0.06$, and 0.094 , respectively. 


\subsection{Selection Results for Power Conditioners Using the Extension Method}

Based on users' capacity demands, this study first arranged the 5-kWP PV modules listed in Table 2 into series and parallel PV arrays (Table 5).

Table 5. 5-kWp series/parallel PV arrays.

\begin{tabular}{ccccc}
\hline Module No. & Wattage (W) per Piece & Material and Structure & Number of Modules & Number of Series/Parallels \\
\hline Module A & 305 & Polycrystalline & 16 & $8 \mathrm{~s} 2 \mathrm{p}$ \\
Module B & 305 & Polycrystalline & 16 & $8 \mathrm{~s} 2 \mathrm{p}$ \\
Module C & 305 & Polycrystalline & 16 & $8 \mathrm{~s} p$ \\
Module D & 305 & Polycrystalline & 16 & $8 \mathrm{~s} 2 \mathrm{p}$ \\
Module E & 305 & Polycrystalline & 16 & $8 \mathrm{~s} 2 \mathrm{p}$ \\
Module F & 305 & Polycrystalline & 16 & $8 \mathrm{~s} 2 \mathrm{p}$ \\
Module G & 305 & Monocrystalline & 16 & $8 \mathrm{~s} 2 \mathrm{p}$ \\
Module H & 305 & Monocrystalline & 16 & $8 \mathrm{~s} 2 \mathrm{p}$ \\
Module I & 305 & Monocrystalline & 16 & $8 \mathrm{~s} 2 \mathrm{p}$ \\
Module J & 305 & Monocrystalline & 16 & $10 \mathrm{~s} 1 \mathrm{p}+6 \mathrm{~s} 1 \mathrm{p}$ \\
Module K & 305 & Monocrystalline & 16 & $10 \mathrm{~s} 1 \mathrm{p}+6 \mathrm{~s} 2 \mathrm{p}$ \\
Module L & 160 & CIGS & 32 & $8 \mathrm{~s} 4 \mathrm{p}$ \\
Module M & 155 & CIGS & 32 & $8 \mathrm{~s} 4 \mathrm{p}$ \\
Module N & 130 & CIGS & 40 & $8 \mathrm{~s} 5 \mathrm{p}$ \\
Module O & 140 & CIGS & 36 & $4 \mathrm{~s} 4 \mathrm{p}+4 \mathrm{~s} 5 \mathrm{p}$ \\
Module P & 150 & CIGS & 34 & $6 \mathrm{~s} 4 \mathrm{p}+5 \mathrm{~s} 2 \mathrm{p}$ \\
Module Q & 145 & CIGS & 36 & $3 \mathrm{~s} 6 \mathrm{p}+3 \mathrm{~s} 6 \mathrm{p}$ \\
\hline
\end{tabular}

Notes: (1) Number of Modules: The number of modules arranged in series or parallel to produce the 5-kWP PV arrays. (2) Number of Series/Parallels: Parallel PV modules are denoted by $p$ and series PV modules are denoted by s. For example, 11s2p represents a PV array with $11 \mathrm{PV}$ modules arranged in series and 2 arranged in parallel, and $11 s 2 p+12 s 1 p$ represents $2 \mathrm{PV}$ arrays, one with $11 \mathrm{PV}$ modules arranged in series and 2 arranged in parallel, and the other with $12 \mathrm{PV}$ modules arranged in series and 1 arranged in parallel.

Table 6 shows the test results for selecting the optimal power conditioner by using the series/parallel PV arrays using the extension evaluation system and series/parallel PV arrays tabulated in Table 5. Among the eight power conditioners corresponding to the 5-kWp PV array produced using Module B (Table 5), Power Conditioners \#3 and \#7 demonstrated the highest correlation degree (0.209157) and were thus the optimal power conditioners. A similar method could be applied to identify the optimal power conditioners for the remaining PV arrays. 
Table 6. Selecting the optimal power conditioners for the 5-kWp PV arrays.

\begin{tabular}{|c|c|c|c|c|c|c|c|c|c|c|}
\hline Module No. & $\begin{array}{l}\text { Wattage } \\
\text { per Piece }\end{array}$ & $\begin{array}{l}\text { Material and } \\
\text { Structure }\end{array}$ & $\begin{array}{c}\text { Power } \\
\text { Conditioner } \\
\# 1\end{array}$ & $\begin{array}{c}\text { Power } \\
\text { Conditioner } \\
\# 2\end{array}$ & $\begin{array}{c}\text { Power } \\
\text { Conditioner } \\
\# 3\end{array}$ & $\begin{array}{c}\text { Power } \\
\text { Conditioner } \\
\# 4\end{array}$ & $\begin{array}{c}\text { Power } \\
\text { Conditioner } \\
\# 5\end{array}$ & $\begin{array}{c}\text { Power } \\
\text { Conditioner } \\
\# 6\end{array}$ & $\begin{array}{c}\text { Power } \\
\text { Conditioner } \\
\# 7\end{array}$ & $\begin{array}{c}\text { Power } \\
\text { Conditioner } \\
\# 8 \\
\end{array}$ \\
\hline Module A & 305 & Poly-crystalline & -1.382207 & 0.046389 & $\underline{0.166370}$ & -1.150779 & -1.150780 & 0.067641 & $\underline{0.166370}$ & -0.299449 \\
\hline Module B & 305 & Poly-crystalline & -1.361776 & 0.087106 & 0.209157 & -1.396062 & -1.396060 & 0.197795 & $\overline{0.209157}$ & -0.264394 \\
\hline Module C & 305 & Poly-crystalline & -1.220361 & -0.227300 & $\overline{-0.101488}$ & -1.640361 & -1.640360 & 0.091500 & $\overline{-0.101490}$ & -0.124728 \\
\hline Module D & 305 & Poly-crystalline & -1.075896 & -0.479850 & -0.358114 & -1.835896 & -1.835900 & -0.197610 & -0.358110 & 0.036323 \\
\hline Module E & 305 & Poly-crystalline & -1.269096 & -0.203420 & -0.083126 & -1.689096 & -1.689100 & 0.074536 & -0.083130 & -0.176237 \\
\hline Module F & 305 & Poly-crystalline & -1.228378 & 0.109729 & $\underline{0.232581}$ & -1.262664 & -1.266660 & 0.220918 & $\underline{0.232581}$ & -0.158459 \\
\hline Module G & 305 & Mono-crystalline & -1.429430 & 0.037024 & 0.157015 & -1.198001 & -1.198000 & 0.060186 & $\underline{0.157015}$ & -0.336444 \\
\hline Module H & 305 & Mono-crystalline & -1.129828 & -0.198800 & -0.073548 & -1.549828 & -1.549830 & 0.108909 & -0.073550 & -0.058563 \\
\hline Module I & 305 & Mono-crystalline & -1.327491 & -0.032890 & 0.089157 & -1.516062 & -1.516060 & 0.217795 & 0.089157 & -0.230109 \\
\hline Module J & 305 & Mono-crystalline & -1.889447 & 0.044962 & -0.305020 & -2.000523 & -2.005230 & -0.480820 & -0.305020 & -0.814483 \\
\hline Module K & 305 & Mono-crystalline & -1.804576 & $\underline{\underline{0.017113}}$ & -0.147140 & -1.920362 & -1.920360 & -0.340440 & -0.147140 & -0.742934 \\
\hline Module L & 160 & CIGS & $\underline{0.178224}$ & -0.731430 & -3.602133 & -0.541776 & -0.541780 & -3.124950 & -3.602130 & -3.041539 \\
\hline Module M & 155 & CIGS & -0.026579 & -0.176190 & -2.960000 & $\underline{0.170564}$ & $\underline{0.170564}$ & -2.701750 & -2.960000 & -3.235360 \\
\hline Module N & 130 & CIGS & $\underline{0.125833}$ & -2.239470 & -3.322414 & $\overline{-0.594167}$ & $\overline{-0.594170}$ & -2.654240 & -3.322410 & -3.175826 \\
\hline Module O & 140 & CIGS & $\overline{-1.294864}$ & 0.101285 & $\underline{0.249786}$ & -1.410650 & -1.410650 & 0.219668 & $\underline{0.249786}$ & -0.222463 \\
\hline Module P & 150 & CIGS & -0.062581 & -0.780020 & $\overline{-1.095152}$ & $\underline{0.134562}$ & $\underline{0.134562}$ & -0.664170 & $\overline{-1.095150}$ & -0.988782 \\
\hline Module Q & 145 & CIGS & -1.456729 & 0.083605 & $\underline{0.224774}$ & $\overline{-1.495371}$ & $\overline{-1.495370}$ & 0.189364 & $\underline{0.224774}$ & -0.354609 \\
\hline
\end{tabular}

The bold and underlined numbers indicate the highest correlation degree. 


\section{Optimal PV-PGS Collocation}

Creating PV-PGSs with an optimal PV module/power conditioner collocation is a key topic of discussion in related fields. Therefore, optimal collocation may vary depending on different factors of consideration of the users. In other words, even when the same PV modules are employed, different power conditioners may be required to optimize the PV-PGS for specific user demands. Based on the different factors of consideration presented in Section 3, the current study employed the extension evaluation system to select candidate PV modules shown in Table 2. The power conditioner selection optimization method presented in Section 4 was then employed to develop an optimal collocation strategy for the PV-PGSs.

Based on the different factors of consideration presented in Section 3, this study first employed the extension evaluation system to select the candidate PV modules shown in Table 2 and produce compact PV arrays suitable for household use. These candidate PV modules were arranged in series and parallel to form the 5-kWp PV arrays. Table 7 shows the module number, wattage, material and structure, quantity of the series/parallel PV modules, and MPPT values required for the power conditioners.

Table 8 tabulates the optimal PV-PGS collocation test results, where the compact 5-kWp PV arrays produced using the candidate PV modules shown in Table 7 were combined with the power conditioners selected using the optimal power conditioner selection method presented in Section 4 . For example, as shown in Table 8, the degree of correlation between the compact 5-kWp PV arrays produced using Module I and Power Conditioner \#3 was 0.232581 , which was the highest correlation value among all the power conditioner brands. In other words, this collocation of the PV array and power conditioner was the optimal selection.

Table 7. Compact 5-kWp systems produced using the precedent PV modules.

\begin{tabular}{ccccc}
\hline Module No. & Wattage $(\mathbf{W})$ per Piece & Material and Structure & Numbers & Number of Series/Parallels \\
\hline Module D & 305 & Polycrystalline & 16 & $8 \mathrm{~s} 2 \mathrm{p}$ \\
Module F & 305 & Polycrystalline & 16 & $8 \mathrm{~s} 2 \mathrm{p}$ \\
Module I & 305 & Monocrystalline & 16 & $8 \mathrm{~s} 2 \mathrm{p}$ \\
Module K & 305 & Monocrystalline & 16 & $10 \mathrm{~s} 1 \mathrm{p}+6 \mathrm{~s} 2 \mathrm{p}$ \\
Module L & 160 & CIGS & 32 & $8 \mathrm{~s} 4 \mathrm{p}$ \\
Module M & 155 & CIGS & 32 & $8 \mathrm{~s} 4 \mathrm{p}$ \\
Module N & 130 & CIGS & 40 & $8 \mathrm{~s} 5 \mathrm{p}$ \\
Module O & 140 & CIGS & 36 & $4 \mathrm{~s} 4 \mathrm{p}+4 \mathrm{~s} 5 \mathrm{p}$ \\
Module P & 150 & CIGS & 34 & $6 \mathrm{~s} 4 \mathrm{p}+5 \mathrm{~s} 2 \mathrm{p}$ \\
\hline
\end{tabular}


Table 8. Optimal PV-PGS collocation test results.

\begin{tabular}{|c|c|c|c|c|c|c|c|c|c|c|}
\hline Module No. & $\begin{array}{c}\text { Wattage }(W) \\
\text { per Piece }\end{array}$ & $\begin{array}{c}\text { Material and } \\
\text { Structure }\end{array}$ & $\begin{array}{c}\text { Power } \\
\text { Conditioner } \\
\# 1\end{array}$ & $\begin{array}{c}\text { Power } \\
\text { Conditioner } \\
\# 2\end{array}$ & $\begin{array}{c}\text { Power } \\
\text { Conditioner } \\
\# 3\end{array}$ & $\begin{array}{c}\text { Power } \\
\text { Conditioner } \\
\# 4\end{array}$ & $\begin{array}{c}\text { Power } \\
\text { Conditioner } \\
\# 5\end{array}$ & $\begin{array}{c}\text { Power } \\
\text { Conditioner } \\
\# 6\end{array}$ & $\begin{array}{c}\text { Power } \\
\text { Conditioner } \\
\# 7\end{array}$ & $\begin{array}{c}\text { Power } \\
\text { Conditioner } \\
\# 8\end{array}$ \\
\hline Module D & 305 & Polycrystalline & -1.075896 & -0.479850 & -0.358114 & -1.835896 & -1.835900 & -0.197610 & -0.358110 & 0.036323 \\
\hline Module F & 305 & Polycrystalline & -1.228378 & 0.109729 & $\underline{0.232581}$ & -1.262664 & -1.266660 & 0.220918 & $\underline{0.232581}$ & -0.158459 \\
\hline Module I & 305 & Monocrystalline & -1.327491 & -0.032890 & $\overline{0.089157}$ & -1.516062 & -1.516060 & $\underline{0.217795}$ & $\overline{0.089157}$ & -0.230109 \\
\hline Module K & 305 & Monocrystalline & -1.804576 & $\underline{0.017113}$ & -0.147140 & -1.920362 & -1.920360 & -0.340440 & -0.147140 & -0.742934 \\
\hline Module L & 160 & CIGS & $\underline{0.178224}$ & $\overline{-0.731430}$ & -3.602133 & -0.541776 & -0.541780 & -3.124950 & -3.602130 & -3.041539 \\
\hline Module M & 155 & CIGS & -0.026579 & -0.176190 & -2.960000 & $\underline{0.170564}$ & $\underline{0.170564}$ & -2.701750 & -2.960000 & -3.235360 \\
\hline Module N & 130 & CIGS & $\underline{0.125833}$ & -2.239470 & -3.322414 & -0.594167 & -0.594170 & -2.654240 & -3.322410 & -3.175826 \\
\hline Module O & 140 & CIGS & -1.294864 & 0.101285 & $\underline{0.249786}$ & -1.410650 & -1.410650 & 0.219668 & $\underline{0.249786}$ & -0.222463 \\
\hline Module P & 150 & CIGS & -0.062581 & -0.780020 & $\overline{-1.095152}$ & $\underline{0.134562}$ & $\underline{0.134562}$ & -0.664170 & $\overline{-1.095150}$ & -0.988782 \\
\hline
\end{tabular}

The bold and underlined numbers indicate the highest correlation degree. 


\section{Conclusions}

This study employed the extension evaluation system to evaluate and select precedent PV modules, which were arranged into compact 5-kWp PV arrays for determining the optimal PV module/PV power conditioner collocation in developing compact PV-PGSs. An extension evaluation model for selecting power conditioners was also developed and used for determining the optimal power conditioner for the various PV arrays. This optimal PV module/PV power conditioner collocation strategy can resolve the challenges PV-PGS designers and installation vendors face when selecting and combining key components. Moreover, the proposed extension evaluation system permits adjusting weighting values according to user preferences to determine customized and optimized collocation.

The mathematical calculation for the proposed extension evaluation system is extremely simple and eliminates the processes of training large amounts of data. In addition, the proposed evaluation system also allows adjusting weighting values according to designer or user preferences, thereby customizing PV-PGSs and determining the optimal collocation for the key components of these systems. Therefore, for a PV-PGS design, the proposed optimal collocation strategy of the PV modules and power conditioners could not only reduce the cost of setting, but also increase the efficiency of power generation. Also, it provides a PV array configuration of the proposed solution in order to meet all the design requirements.

Author Contributions: Conceptualization, P.-Y.C. and K.-H.C.; Writing-Review \& Editing, P.-Y.C and K.-H.C.; Analysis, P.-Y.C.; Data Curation, Software and Experiment, Z.-Y.W.; Administration, K.-H.C.

Funding: This research was funded by Ministry of Science and Technology, Taiwan, under the Grant Number MOST 106-2221-E-167-013-MY2.

Conflicts of Interest: The authors of the manuscript declare that there is no conflict of interest with any of the commercial identities mentioned in the manuscript.

\section{Appendix A.}

The grades of the classical domain and neighborhood domain matter-element models of the various PV modules listed in Table 2 are discussed in the following section.

Appendix A.1. Classical Domain Matter-Element Models of the Various Graded 305-W Polycrystalline PV Modules

$$
\begin{aligned}
& R_{305-P 1}=\left[\begin{array}{lll}
\text { Poly }- \text { Si } & \text { Price } & <0.70,0.725> \\
& \text { Power temperature } & <-0.415,-0.41> \\
& \text { Size } & <0.58532,0.585475> \\
& \text { Weight } & <22.5,22.8>
\end{array}\right] \text { First grade } \\
& R_{305-P 2}=\left[\begin{array}{lll}
\text { Poly }- \text { Si } & \text { Price } \\
& \text { Power temperature } & <-0.426,-0.415> \\
& \text { Size } & <0.585475,0.58663> \\
& \text { Weight } & <22.8,23.5>
\end{array}\right] \text { Second grade } \\
& R_{305-P 3}=\left[\begin{array}{lll}
\text { Poly }- \text { Si } & \text { Price } \\
& \text { Power temperature } & <-0.445,-0.426> \\
& \text { Size } & <0.58663,0.588845> \\
\text { Weight } & <23.5,25>
\end{array}\right] \text { Third grade }
\end{aligned}
$$




$$
\begin{aligned}
& R_{305-P 4}=\left[\begin{array}{lll}
\text { Poly }- \text { Si } & \text { Price } & <0.775,0.8> \\
& \text { Power temperature } & <-0.464,-0.445> \\
& \text { Size } & <0.588845,0.591139> \\
& \text { Weight } & <25,26.5>
\end{array}\right] \text { Fourth grade } \\
& R_{305-P 5}=\left[\begin{array}{lll}
\text { Poly }- \text { Si } & \text { Price } & <0.80,0.825> \\
& \text { Power temperature } & <-0.475,-0.464> \\
& \text { Size } & <0.591139,0.592294> \\
& \text { Weight } & <26.5,27.2>
\end{array}\right] \text { Fifth grade } \\
& R_{305-P 6}=\left[\begin{array}{lll}
\text { Poly }- \text { Si } & \text { Price } & <0.825,0.85> \\
& \text { Power temperature } & <-0.475,-0.48> \\
& \text { Size } & <0.592294,0.592499> \\
& \text { Weight } & <27.2,27.5>
\end{array}\right] \text { Sixth grade }
\end{aligned}
$$

Appendix A.2. Classical Domain Matter-Element Models of the Various Graded 305-W Monocrystalline PV Modules

$$
\begin{aligned}
& R_{305-S 1}=\left[\begin{array}{cll}
\text { Mono }- \text { Si } & \text { Price } & <1,1.06> \\
& \text { Power temperature } & <-0.429,-0.427> \\
& \text { Size } & <0.58532,0.58586> \\
\text { Weight } & <22.5,22.8>
\end{array}\right] \text { First grade } \\
& R_{305-S 2}=\left[\begin{array}{lll}
\text { Mono }- \text { Si } & \text { Price } & <1.06,1.12> \\
& \text { Power temperature } & <-0.433,-0.429> \\
\text { Size } & <0.58586,0.58671> \\
& \text { Weight } & <22.8,23.3>
\end{array}\right] \text { Second grade } \\
& R_{305-S 3}=\left[\begin{array}{lll}
\text { Mono }- \text { Si } & \text { Price } & <1.12,1.18> \\
& \text { Power temperature } & <-0.473,-0.433> \\
& \text { Size } & <0.58671,0.588716> \\
\text { Weight } & <23.3,24.7>
\end{array}\right] \text { Third grade } \\
& R_{305-S 4}=\left[\begin{array}{lll}
\text { Mono }- \text { Si } & \text { Price } & <1.18,1.24> \\
& \text { Power temperature } & <-0.477,-0.473> \\
& \text { Size } & <0.588716,0.589566> \\
& \text { Weight } & <24.7,25.2>
\end{array}\right] \text { Fourth grade } \\
& R_{305-S 5}=\left[\begin{array}{lll}
\text { Mono }- \text { Si } & \text { Price } & <1.24,1.3> \\
& \text { Power temperature } & <-0.479,-0.477> \\
\text { Size } & <0.589566,0.590106> \\
\text { Weight } & <25.2,25.5>
\end{array}\right] \text { Fifth grade }
\end{aligned}
$$


Appendix A.3. Classical Domain Matter-Element Models of the Various Graded 305-W CIGS PV Modules

$$
\begin{aligned}
& R_{\text {CIGS-1 }}=\left[\begin{array}{lll}
\text { CIGS } & \text { Price } & <0.8,0.8> \\
& \text { Power temperature } & <-0.265,-0.26> \\
& \text { Size } & <0.465961,0.466961> \\
& \text { Weight } & <19.5,22.5>
\end{array}\right] \text { First grade } \\
& R_{\text {CIGS-2 }}=\left[\begin{array}{lll}
\text { CIGS } & \text { Price } & <0.8,0.8> \\
& \text { Power temperature } & <-0.435,-0.265> \\
& \text { Size } & <0.466961,0.474081> \\
& \text { Weight } & <22.5,30>
\end{array}\right] \text { Second grade } \\
& R_{\text {CIGS-3 }}=\left[\begin{array}{lll}
\text { CIGS } & \text { Price } & <0.8,0.8> \\
& \text { Power temperature } & <-0.44,-0.435> \\
& \text { Size } & <0.474081,0.475081> \\
& \text { Weight } & <30,33>
\end{array}\right] \text { Third grade }
\end{aligned}
$$

\section{References}

1. Chao, K.H.; Lee, Y.H.; Yen, K.L.; Hung, C.G. Performance Analysis of a Power Conditioner for a Small Scale Grid-Connected PV System. J. Power Electron. 2009, 7, 76-83.

2. Balo, F.; Şağbanşua, L. The Selection of the Best Solar Panel for the Photovoltaic System Design by Using AHP. Energy Procedia 2016, 100, 50-53. [CrossRef]

3. Long, S.P.; Geng, S. Decision Framework of Photovoltaic Module Selection under Interval-valued Intuitionistic Fuzzy Environment. Energy Convers. Manag. 2015, 106, 1242-1250. [CrossRef]

4. Baez-Fernandez, H.; Ramirez-Beltran, N.D.; Mendez-Pinero, M.I. Selection and Configuration of Inverters and Modules for a Photovoltaic System to Minimize Costs. Renew. Sustain. Energ. Rev. 2016, 58, 16-22. [CrossRef]

5. Bureau of Energy, Ministry of Economic Affairs of Taiwan. PV Inverter Registration Website. Available online: https:/ / pvipl.itri.org.tw/t1.aspx (accessed on 4 August 2018).

6. Cai, W. The Extension Set and Non-Compatible Problem. Sci. Explor. 1983, 3, 83-97.

7. Bureau of Energy, Ministry of Economic Affairs of Taiwan. PV Module Registration Website. Available online: http:/ /www.tcpv.org.tw/ (accessed on 4 August 2018).

8. Chao, K.H.; Li, C.J. An Intelligent Maximum Power Point Tracking Method Based on Extension Theory for PV Systems. Expert Syst. Appl. 2010, 37, 1050-1055. [CrossRef]

9. Chao, K.H.; Chen, P.Y. An Intelligent Fault Diagnosis Method Based-on Extension Theory for DC-AC Converters. Int. J. Fuzzy Syst. 2015, 17, 105-115. [CrossRef]

10. Neo Solar Power Corporation. Available online: https://www.nsp.com/?lang=en (accessed on 17 September 2018).

11. Neo Solar Power Corporation. Available online: https://www.nsp.com/nspsolarcells?lang=en (accessed on 17 September 2018).

12. Apollo Solar Energy. Available online: http://www.asectw.com/ASEC_tw_index.aspx (accessed on 4 September 2018).

13. Anji Technology Co Ltd. Available online: http://www.anjitek.com/cht/ (accessed on 4 September 2018).

14. Ritek Corporation. Available online: http:/ /www.ritek.com.tw/ (accessed on 4 September 2018).

15. Ligitek Photovoltaic Co Ltd. Available online: http://www.ligitek-pv.com.tw/contact.html (accessed on 18 September 2018).

16. Solartech Energy Corp. Available online: http://en.solartech-energy.com/about/ (accessed on 17 September 2018).

17. NexPower Technology Corp. March 2014. Available online: https://www.nexpw.com/?aspxerrorpath= /about (accessed on 17 September 2018). 
18. Jenn Feng New Energy. March 2014. Available online: http://www.jennfeng.com/index.asp?lang=1 (accessed on 18 September 2018).

19. Sunshine PV Corp. Available online: http:/ / www.sunshine-pv.com (accessed on 17 September 2018).

20. Delta Electronics Inc. Available online: http:/ / www.deltaww.com/ (accessed on 17 September 2018).

21. Sma Company. Available online: http://www.sma.de/en.html (accessed on 17 September 2018).

22. Ablerex Electronics Co Ltd. March 2014. Available online: http://www.ablerex.com.tw/usa/ (accessed on 17 September 2018).

23. Motech Industries Inc. Available online: http://www.motechsolar.com/en/aboutus.php (accessed on 17 September 2018).

24. Allis Electric Co Ltd. Available online: http://www.allis.com.tw (accessed on 17 September 2018).

25. Power Master Technology Co Ltd. Available online: http://www.powermaster.com.tw/ (accessed on 17 September 2018).

26. Prime Volt Co Ltd. Available online: http://www.primevolt.com/index.php?option=com_content\&view= article\&id $=47 \&$ Itemid $=55$ (accessed on 17 September 2018).

27. Yama-Sun Energy Technology Co Ltd. Available online: http://www.yamasun.com.tw/activity.php\# (accessed on 17 September 2018).

28. Chu, C.P. Analytic Hierarchy Process Theory; Department of Business Administration, National Dong Hwa University: Hualien, Taiwan, 2009.

(C) 2018 by the authors. Licensee MDPI, Basel, Switzerland. This article is an open access article distributed under the terms and conditions of the Creative Commons Attribution (CC BY) license (http://creativecommons.org/licenses/by/4.0/). 